Organic Electronic Devices

Subscriber access provided by King Abdullah University of Science and Technology Library

\title{
Pronounced Side Chain Effects in Triple Bond- Conjugated Polymers Containing Naphthalene Diimides for $n$-Channel Organic Field-Effect Transistors
}

Sungho Nam, Suk Gyu Hahm, Dongyoon Khim, Hwajeong Kim, Tissa Sajoto, Moonhor

Ree, Seth R. Marder, Thomas D. Anthopoulos, Donal D.C. Bradley, and Youngkyoo Kim

ACS Appl. Mater. Interfaces, Just Accepted Manuscript • DOI: 10.1021/acsami.8b01196 • Publication Date (Web): 23 Mar 2018

Downloaded from http://pubs.acs.org on April 4, 2018

\section{Just Accepted}

"Just Accepted" manuscripts have been peer-reviewed and accepted for publication. They are posted online prior to technical editing, formatting for publication and author proofing. The American Chemical Society provides "Just Accepted" as a service to the research community to expedite the dissemination of scientific material as soon as possible after acceptance. "Just Accepted" manuscripts appear in full in PDF format accompanied by an HTML abstract. "Just Accepted" manuscripts have been fully peer reviewed, but should not be considered the official version of record. They are citable by the Digital Object Identifier (DOI®). "Just Accepted" is an optional service offered to authors. Therefore, the "Just Accepted" Web site may not include all articles that will be published in the journal. After a manuscript is technically edited and formatted, it will be removed from the "Just Accepted" Web site and published as an ASAP article. Note that technical editing may introduce minor changes to the manuscript text and/or graphics which could affect content, and all legal disclaimers and ethical guidelines that apply to the journal pertain. ACS cannot be held responsible for errors or consequences arising from the use of information contained in these "Just Accepted" manuscripts. 


\title{
Pronounced Side Chain Effects in Triple Bond-Conjugated
}

\section{Polymers Containing Naphthalene Diimides for n-Channel}

\section{Organic Field-Effect Transistors}

\author{
Sungho Nam ${ }^{\dagger, \ddagger, \#, ~ S u k ~ G y u ~ H a h m ~}{ }^{\S, \|, \#, D o n g y o o n} K_{\text {Kim }}^{\perp}$, Hwajeong Kim ${ }^{\dagger,}{ }^{,}$, Tissa Sajoto", \\ Moonhor Ree ${ }^{\S}$, Seth R. Marder", Thomas D. Anthopoulos ${ }^{\perp, \otimes}$, Donal D. C. Bradley ${ }^{*,+\pi}$ and \\ Youngkyoo Kim ${ }^{*} \dagger$
}

'Organic Nanoelectronics Laboratory and KNU Institute for Nanophotonics Applications, Department of Chemical Engineering, School of Applied Chemical Engineering, Kyungpook National University, Daegu 41566, Republic of Korea

"Department of Physics, Division of Mathematical, Physical and Life Sciences, University of Oxford, Oxford OX1 3PD, United Kingdom

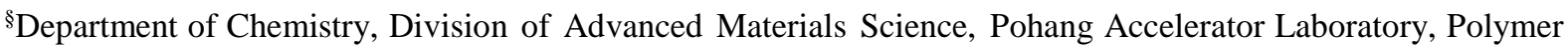
Research Institute, and BK School of Molecular Science, Pohang University of Science and Technology, Pohang 37673, Republic of Korea

"School of Chemistry and Biochemistry and Center for Organic Photonics and Electronics, Georgia Institute of Technology, Atlanta, GA 30332-0400, United States of America

${ }^{\perp}$ Center for Plastic Electronics, Department of Physics, Blackett Laboratory, Imperial College London, London SW7 2AZ, United Kingdom

${ }^{\nabla}$ Priority Research Center, Research Institute of Advanced Energy Technology, Kyungpook National University, Daegu 41566, Republic of Korea

$\otimes$ Division of Physical Sciences and Engineering, King Abdullah University of Science and Technology, Thuwal 23955, Saudi Arabia

IDepartments of Engineering Science, Division of Mathematical, Physical and Life Sciences, University of Oxford, Oxford OX1 3PJ, United Kingdom

\#S. Nam and S. G. Hahm contributed equally to this work.

*Corresponding Author: Prof. Youngkyoo Kim

Email) ykimm@knu.ac.kr; Tel) +82-53-950-5616 


\begin{abstract}
:
Three triple bond-conjugated naphthalene diimide (NDI) copolymers, poly[[N,N'-bis(2-R $\left.{ }_{1}\right)-$ naphthalene-1,4,5,8-bis(dicarboximide)-2,6-diyl]-alt-[(2,5-bis(2- $\left.\mathrm{R}_{2}\right)-1,4-$ phenylene)bis(ethyn-2,1-diyl]\} (PNDIR $\left.{ }_{1}-\mathrm{R}_{2}\right)$, were synthesized via Sonogashira coupling polymerization with varying alkyl side chains at the nitrogen-atoms of the imide ring and 2,5positions of the 1,4-diethynylbenzene moiety. Considering their identical polymer backbone structures, the side chains were found to have a strong influence on the surface morphology/nanostructure, thus playing a critical role in charge-transporting properties of the three NDI-based copolymers. Among the polymers, the one with an octyldodecyl (OD) chain at the nitrogen-atoms of imide ring and hexadecyloxy $(\mathrm{HO})$ chain at the 2,5-positions of 1,4diethynylbenzene, $\mathrm{P}(\mathrm{NDIOD}-\mathrm{HO})$, exhibited the highest electron mobility of $0.016 \mathrm{~cm}^{2} \mathrm{~V}^{-1} \mathrm{~s}^{-1}$, as compared to NDI-based copolymers with an ethylhexyl (EH) chain at the 2,5-positions of 1,4-diethynylbenzene. The enhanced charge mobility in the $\mathrm{P}(\mathrm{NDIOD}-\mathrm{HO})$ layers is attributed to the well-aligned nanofiber-like surface morphology and highly ordered packing structure with a dominant edge-on orientation, thus enabling efficient in-plane charge transport. Our results on the molecular structure-charge transport property relationship in these materials may provide an insight into novel design of n-type conjugated polymers for applications in the organic electronics of the future.
\end{abstract}

KEYWORDS: side chain engineering, triple bond-conjugated, naphthalene diimide, fieldeffect transistor, chain orientation 


\section{INTRODUCTION}

Impressive progress in development of solution-processable n-type conjugated polymers has been achieved over the past three decades for their potential applications in flexible organic electronics such as field-effect transistors, solar cells, and memory devices. ${ }^{1-6} \mathrm{~A}$ variety of n-type polymers with high electron mobilities have been reported by introducing electron-deficient moieties such as benzothiadiazole (BT), isoindigo (IID), diketopyrrolopyrrole (DPP), as well as naphthalene diimide and perylene diimide (NDI and PDI). ${ }^{7-19}$ Among those electron-deficient units, in particular, NDI moieties have proved to be the most promising building block due to their high thermal and photochemical stability, lowlying lowest unoccupied molecular orbital (LUMO) energy level, and coplanar structure, leading to strong intermolecular interaction. ${ }^{20-22}$

Correlations between device performance and structure of NDI-based copolymers have been extensively investigated by incorporating the NDI unit into a series of thiophene-based, selenophene-based, and fluorene-based linkers. ${ }^{11,19,23-32}$ In addition, side chain engineering especially at the nitrogen-atoms of the imide ring with linear or branched alkyl chains, hybrid siloxane chains, and semifluoroalkyl side chains, etc., is a key strategy to control their solubilities, nanostructures, and self-assembly capabilities. ${ }^{33-35}$ Appropriate selections of bridging groups (linkers) and side chains can influence the charge-transporting properties in NDI-based copolymers, and thus device performance. Very recently, the copolymer comprising NDI-bithiophene (T2), demonstrated the remarkable electron mobility of 6.4 $\mathrm{cm}^{2} \mathrm{~V}^{-1} \mathrm{~s}^{-1}$ with high performance uniformity by employing bar-coating deposition technique and polymer/polymer solar cells consisting of $\mathrm{P}(\mathrm{NDI} 2 \mathrm{OD}-\mathrm{T} 2)$ as an electron-acceptor reached a power conversion efficiency of $8.27 \% .{ }^{36-37}$ Moreover, NDI-thienylene-vinylenethienylene (TVT) with semifluoroalkyl side chains (PNDIF-TVT) exhibited a high electron 
mobility of $6.5 \mathrm{~cm}^{2} \mathrm{~V}^{-1} \mathrm{~s}^{-1}$ because of the side chain-induced strong self-organization. ${ }^{38}$

Compared to the development of high-performance NDI-based copolymers, NDI-based copolymers with triple bond-linkers have not been investigated in sufficient detail, considering their possible advantages, such as high air stability, long effective conjugation through the polymer chain direction and alleviated steric hindrance. ${ }^{39-45}$ Additionally, triple bond-conjugated polymers can be synthesized by Sonogashira coupling, which circumvents issues related to the highly toxic organo-tin compounds required for Stille coupling and in situ degradation of monomers in Suzuki coupling. ${ }^{39-40}$

The three NDI-based copolymers with 1,4-diethylnylbenzene linkers described herein have been previously reported, but their electron mobility was low $\left(10^{-4}-10^{-3} \mathrm{~cm}^{2} \mathrm{~V}^{-1} \mathrm{~s}^{-1}\right)$ and their structure-device performance relationship was not fully examined. ${ }^{43}$ Therefore, we investigated the correlation between the electrical characteristics and nanostructure/surface morphology of the triple bond-conjugated NDI-based copolymers with different alkyl side chains at the nitrogen-atoms of the imide ring and at the 2,5-positions of the 1,4diethynylbenzene bridging group. The alkyl side chains at the nitrogen-atoms of the imide ring and 2,5-positions of the 1,4-diethynylbenzene linker were found to have a critical impact on the polymer chain ordering as well as surface morphology, leading to the charge transport properties of the resulting transistors.

\section{EXPERIMENTAL SECTION}

2.1. Synthesis of $\mathbf{P}($ NDIO-EH) Polymer. All chemicals were purchased from SigmaAldrich and were used as received without further purification unless stated otherwise. The synthesis of $\mathrm{P}(\mathrm{NDIO}-\mathrm{EH})$ is described below.

Synthesis of N,N'-bis(octyl)-2,6-dibromonaphthalene-1,4,5,8-bis(dicarboximide) 
(NDIO). 2,6-dibromo-1,4,5,8-naphthalenetetracarboxylic acid dianhydride was synthesized according to a literature reported procedure. ${ }^{43} 2.00 \mathrm{~g}(4.8 \mathrm{mmol})$ of crude 2,6-dibromo1,4,5,8-naphthalenetetracarboxylic acid dianhydride was added to $200 \mathrm{~mL}$ of glacial acetic acid. The reaction mixture was heated to $130^{\circ} \mathrm{C}$ for $1 \mathrm{~h}$ under nitrogen atmosphere to give a yellow solution. $2.35 \mathrm{~g}(19.2 \mathrm{mmol})$ of $\mathrm{N}$-octylamine was added to the reaction mixture via syringe. The reaction mixture was heated at $130{ }^{\circ} \mathrm{C}$ for $1 \mathrm{~h}$ to yield a dark brown colored solution, and then cooled down to room temperature. The red-brownish solid was filtered and washed with $200 \mathrm{~mL}$ of distilled water twice and $500 \mathrm{~mL}$ of methanol, and then air-dried. $1.42 \mathrm{~g}$ (2.26 mmol, $47 \%$ yield $)$ of yellow/salmon-colored solid product was obtained by silica gel column chromatography using dichloromethane as the eluent. ${ }^{1} \mathrm{H}$ NMR $(\mathrm{CDCl} 3,300$ $\mathrm{MHz}), \delta(\mathrm{ppm})): 9.00(\mathrm{~s}, 2 \mathrm{H}), 4.15(\mathrm{~m}, 4 \mathrm{H}), 2.25(\mathrm{~m}, 4 \mathrm{H}), 1.36(\mathrm{~m}, 20 \mathrm{H}), 0.93(\mathrm{~m}, 6 \mathrm{H})$.

Synthesis of poly[[N,N'-bis(2-octyl)-naphthalene-1,4,5,8-bis(dicarboximide)-2,6-diyl]alt-[(2,5-bis(2-ethyl-hexyl)-1,4-phenylene)bis(ethyn-2,1-diyl]) (P(NDIO-EH)).

$0.38 \mathrm{~g}(0.586 \mathrm{mmol})$ of NDIO was added to a Schlenk flask containing a stirring bar. 0.205 $\mathrm{g}(0.586 \mathrm{mmol})$ of 1,4-bis(2-ethylhexyl)-2,5-diethynylbenzene $(\mathrm{EH})$ was dissolved in $5 \mathrm{~mL}$ of toluene and then added to a Schlenk vessel via syringe under nitrogen atmosphere. Additional $5 \mathrm{~mL}$ of anhydrous toluene and $10 \mathrm{~mL}$ of diisopropyl amine were added via syringe. $29 \mathrm{mg}$ $0.0410 \mathrm{mmol})$ of $\mathrm{PdCl}_{2}\left(\mathrm{PPh}_{3}\right)_{2}$ and $7.8 \mathrm{mg}(0.0410 \mathrm{mmol})$ of copper(I) iodide were added to the reaction mixture. The reaction mixture was pump-filled with nitrogen three times, stirred for $15 \mathrm{~min}$ at room temperature, and then heated at $80{ }^{\circ} \mathrm{C}$ for $3 \mathrm{~d}$. The reaction mixture was cooled down to room temperature and was added dropwise to $300 \mathrm{~mL}$ of methanol, and then the resulting solid was filtered. The blackish solid product was purified by Soxhlet extraction with methanol, acetone, hexane, and chloroform. The chloroform extracts were precipitated into methanol and dried in a vacuum oven. $400 \mathrm{mg}$ (0.462 mmol, $79 \%$ yield) of P(NDIO- 
EH) polymer was obtained. GPC (after Soxhlet) in $\mathrm{CHCl}_{3}$ : weight-average molecular weight $(\mathrm{Mw})=7.5 \mathrm{kDa}$; polydispersity index $(\mathrm{PDI})=1.56 .{ }^{1} \mathrm{H} \mathrm{NMR}(\mathrm{CDCl} 3,500 \mathrm{MHz}, \delta$ (ppm)): 8.83 (br, 2H), 7.60 (br, 2H), 4.23 (br, 4H), 3.04 (br, 4H), 1.79-0.89 (br, 60H) (see Figure S1).

2.2. Transistor Fabrication and Characterization. $\mathrm{P}(\mathrm{NDIO}-\mathrm{EH})$ solution was prepared using chloroform and $\mathrm{P}(\mathrm{NDIOD}-\mathrm{EH})$ and $\mathrm{P}(\mathrm{NDIOD}-\mathrm{HO})$ solutions were dissolved in chlorobenzene at a solid concentration of $5 \mathrm{mg} / \mathrm{mL}$ and were vigorously stirred at $50{ }^{\circ} \mathrm{C}$ overnight. $\mathrm{P}(\mathrm{NDIOD}-\mathrm{EH})$ and $\mathrm{P}(\mathrm{NDIOD}-\mathrm{HO})$ were used as prepared for the previously reported study. ${ }^{43}$ The fluoropolymer dielectric, CYTOP, was used as received from Asahi Glass. The glass substrates were cleaned in an ultrasonic bath for $20 \mathrm{~min}$ in acetone and isopropyl alcohol, and subsequently dried with nitrogen flow. ${ }^{46} \mathrm{Al}(\sim 5 \mathrm{~nm})$ and $\mathrm{Au}(\sim 30 \mathrm{~nm})$ were sequentially thermally evaporated onto glass substrates using shadow masks to form source-drain (S-D) electrodes with 1000 and $30 \mu \mathrm{m}$ channel width and length, respectively (note that the thin $\mathrm{Al}$ layer was used as an adhesion layer between $\mathrm{Au}$ and glass substrates). ${ }^{47}$ NDI-based copolymers $(\sim 20 \mathrm{~nm})$ were spin-coated at $1500 \mathrm{rpm}$ for $30 \mathrm{~s}$ on glass substrates with $\mathrm{Al} / \mathrm{Au}$ electrodes, and subsequently annealed at $120{ }^{\circ} \mathrm{C}$ for $15 \mathrm{~min}$. Next, CYTOP ( 900 $\mathrm{nm}$ ) as gate dielectrics was spun on the NDI-based copolymers at $2000 \mathrm{rpm}$ for $60 \mathrm{~s}$ and annealed at $60{ }^{\circ} \mathrm{C}$ for $3 \mathrm{~h}$. Aluminum $(\sim 60 \mathrm{~nm})$ as gate electrodes were deposited by thermal evaporation using shadow masks.

2.3. Measurements. The film thickness was measured using a Tencor Alpha Step 200 profilometer. UV-visible absorption spectra of the thin films were recorded using a PerkinElmer Lambda $750 \mathrm{UV} /$ Vis/NIR spectrophotometer. The ionization potentials of 
polymers were obtained using a Riken-Keiki AC2 photoelectron spectrometer with a UV light source (UV intensity $=10 \mathrm{nW}$ under an anode bias voltage of $3000 \mathrm{~V}$, measurement range: from 3.8 to $6.2 \mathrm{eV}$ by increasing $0.05 \mathrm{eV}$ ). The transistor characteristics were measured inside a nitrogen-filled glove box using a 2-channel Agilent B2986 system. The operational stability of devices was obtained in air on a Keithley 4200 SCS and Microtech Cascade probe station. Atomic force microscope (AFM) measurement was performed on a Bruker Nanoscope V Multimode 8 to study the surface morphology of the thin films and a synchrotron-radiation grazing incidence X-ray diffraction (GIXD) measurement (X-ray wavelength $(\lambda)=1.2435 \AA$, incidence angle $=0.14^{\circ}, 3 \mathrm{C}$, SAXS I beamline, Pohang Accelerator Laboratory) was carried out to investigate the nanostructure of thin films.

\section{RESULTS AND DISCUSSION}

As shown in Figure 1a, a series of triple bond-conjugated NDI-based copolymers, denoted as $\mathrm{P}\left(\mathrm{NDIR}_{1}-\mathrm{R}_{2}\right)$, was prepared by Sonogashira coupling of $\mathrm{N}, \mathrm{N}^{\prime}$-bis $\left(2-\mathrm{R}_{1}\right)$ naphthalene-1,4,5,8-bis(dicarboximide) and 1,4-bis(2- $\left.\mathrm{R}_{2}\right)$-2,5-diethynylbenzene. The differences among the three $\mathrm{P}\left(\mathrm{NDI}-\mathrm{R}_{1}-\mathrm{R}_{2}\right)$ polymers were the alkyl chains $\left(\mathrm{R}_{1}=\right.$ n-octyl $(\mathrm{O})$ or octyldodecyl (OD)) at the nitrogen-atoms of the imide rings and alkyl chains $\left(\mathrm{R}_{2}=\right.$ ethylhexyl (EH) or hexadecyloxy $(\mathrm{HO})$ ) at the 2,5-positions of the 1,4-diethylnylbenzene moiety (see Figure $1 \mathrm{~b}$ ). A systematic study of the electrical characteristics of $\mathrm{P}\left(\mathrm{NDI}-\mathrm{R}_{1}-\mathrm{R}_{2}\right)$ polymers was carried out by fabricating top-gate/bottom-contact transistors (see Figure 1c).

Figure 1 
We first investigated the UV-visible absorption spectra of NDI-based copolymers in solid state and solution, which are significantly influenced by the side chains attached to backbone (see Figure 2a and S2a). The NDI-based copolymers exhibited two distinctive absorption bands in the high- $(350-450 \mathrm{~nm})$ and low-energy $(500-750 \mathrm{~nm})$ regions, which was equivalent to a $\pi-\pi^{*}$ transition and intramolecular charge transfer (ICT), respectively. Interestingly, despite the identical optical band gaps $\left(\mathrm{E}_{\mathrm{g}} \approx 2.0 \mathrm{eV}\right)$ of the $\mathrm{P}(\mathrm{NDIO}-\mathrm{EH})$ and $\mathrm{P}(\mathrm{NDIOD}-\mathrm{EH})$ polymer thin films, the $\mathrm{P}(\mathrm{NDIOD}-\mathrm{EH})$ thin film showed a more distinct ICT peak than the $\mathrm{P}(\mathrm{NDIO}-\mathrm{EH})$ thin film, which was ascribed to its distinct intermolecular interactions. More importantly, $\mathrm{P}(\mathrm{NDIOD}-\mathrm{HO})$ thin films exhibited a pronounced absorption in the deep red and/or near-infrared region $(<750 \mathrm{~nm})$, corresponding to an $\mathrm{E}_{\mathrm{g}}$ of $\sim 1.6 \mathrm{eV}$. The red-shifted (ca. $100 \mathrm{~nm}$ ) absorption for the P(NDIOD-HO) thin film can be primarily ascribed to the increased ICT character due to the presence of an electron-rich dialkoxy side chain. We found the marginal change in the absorption spectra of as-spun and annealed thin films, indicative of the chain aggregation during spin-coating (see Figure S2b). As can be seen from Figure $2 b$, photoelectron yield spectra (PEYS) of the three polymer thin films were obtained to evaluate their highest occupied molecular orbital (HOMO) energy levels. Deep HOMO energy levels of $-5.8 \mathrm{eV}$ and $-6.1 \mathrm{eV}$ were determined for $\mathrm{P}(\mathrm{NDIO}-\mathrm{EH})$ and $\mathrm{P}(\mathrm{NDIOD}-\mathrm{EH})$ thin films, respectively, whereas $\mathrm{P}(\mathrm{NDIOD}-\mathrm{HO})$ exhibited a lower HOMO energy level of $-5.7 \mathrm{eV}$ owing to the presence of electron-donating dialkoxy side chains. Finally, the LUMOs of P(NDIO-EH), P(NDIOD-EH), and P(NDIOD-HO) were obtained as $3.8,-4.1$, and $-4.1 \mathrm{eV}$, respectively (note that the LUMO energy levels were calculated from the optical band gap energy and the HOMO energy levels). Regarding the charge injection barrier between the $\mathrm{Al} / \mathrm{Au}$ electrode and $\mathrm{HOMO} / \mathrm{LUMO}$ energy levels $\left(\Delta \mathrm{E}_{\mathrm{Al} / \mathrm{Au}-\mathrm{HOMO}}=\mathrm{ca}\right.$. $1.0-1.4 \mathrm{eV}$ and $\left.\Delta \mathrm{E}_{\mathrm{Al} / \mathrm{Au}-\mathrm{LUMO}}=\mathrm{ca} .0 .6-0.9 \mathrm{eV}\right)$, electron injection was more favorable than 
hole injection (see Figure 2c). Overall, these results show that the optical and electronic properties are significantly influenced by the side chains at the nitrogen-atoms of the imide rings and 2,5-positions of 1,4-diethynylbenzene; thus, we can expect that the device performance would be influenced by different side chains.

\section{Figure 2}

As prepared transistors exhibited n-type behaviour with clear drain-source current drain voltage $\left(I_{D}-V_{D}\right.$, output curves $)$ and $I_{D}$ versus gate voltage $\left(V_{G}\right)$ transfer characteristics (Figure 3a). Importantly, all polymers exhibit minimal operating hysteresis implying the absence of significant electron trapping and/or mobile ion accumulation at the gate insulator/semiconductor interface. Notably, $\mathrm{I}_{\mathrm{D}}$ at $\mathrm{V}_{\mathrm{D}}$ and $\mathrm{V}_{\mathrm{G}}$ of $100 \mathrm{~V}$ for $\mathrm{P}(\mathrm{NDIOD}-\mathrm{EH})$ and $\mathrm{P}(\mathrm{NDIOD}-\mathrm{HO})$ polymers with octyldodecyl (OD) chains at the nitrogen-atoms of the imide ring was much higher than that for $\mathrm{P}(\mathrm{NDIO}-\mathrm{EH})$ with an n-octyl $(\mathrm{O})$ chain at the nitrogenatoms of the imide ring (Figure $3 b)$. In addition, a relatively high threshold voltage $\left(\mathrm{V}_{\mathrm{TH}}\right)$ for the $\mathrm{P}(\mathrm{NDIO}-\mathrm{EH})$ device $\left(\mathrm{V}_{\mathrm{TH}}=\right.$ ca. $\left.42.8 \mathrm{~V}\right)$ was found, whereas the $\mathrm{P}(\mathrm{NDIOD}-\mathrm{EH})$ and $\mathrm{P}(\mathrm{NDIOD}-\mathrm{HO})$ devices showed relatively low $\mathrm{V}_{\mathrm{TH}}$ values of ca. 31.3 and $30.7 \mathrm{~V}$, respectively (Figure S3). The relatively better device performance in terms of $\mathrm{V}_{\mathrm{TH}}$ and $\mu_{\mathrm{e}}$ for the $\mathrm{P}(\mathrm{NDIOD}-\mathrm{EH})$ and $\mathrm{P}(\mathrm{NDIOD}-\mathrm{HO})$ polymers, can be ascribed to the relatively low electron injection barrier from the S-D electrodes to the LUMO energy levels of P(NDIOD-EH) and $\mathrm{P}(\mathrm{NDIOD}-\mathrm{HO})$ as compared to that of $\mathrm{P}(\mathrm{NDIO}-\mathrm{EH})\left(\Delta \mathrm{E}_{\mathrm{Al} / \mathrm{Au}-\mathrm{LUMO}}=\mathrm{ca} \cdot 0.6 \mathrm{eV}\right.$ for $\mathrm{P}(\mathrm{NDIOD}-\mathrm{EH})$ and $\mathrm{P}(\mathrm{NDIOD}-\mathrm{HO})$ polymers and $\Delta \mathrm{E}_{\mathrm{Al} / \mathrm{Au}-\mathrm{LUMO}}=\mathrm{ca} .0 .9 \mathrm{eV}$ for $\mathrm{P}(\mathrm{NDIO}-\mathrm{EH})$ polymer). Importantly, the $\mathrm{P}(\mathrm{NDIOD}-\mathrm{HO})$ transistor exhibited the highest electron mobility $\left(\mu_{\mathrm{e}}\right)$ of $0.016 \mathrm{~cm}^{2} \mathrm{~V}^{-1} \mathrm{~s}^{-1}$, whereas the $\mathrm{P}(\mathrm{NDIO}-\mathrm{EH})$ and $\mathrm{P}(\mathrm{NDIOD}-\mathrm{EH})$ devices showed 
relatively low $\mu_{\mathrm{e}}$ values of 0.0011 and $0.009 \mathrm{~cm}^{2} \mathrm{~V}^{-1} \mathrm{~s}^{-1}$, respectively. However, P(NDIODHO) transistors annealed at above $120^{\circ} \mathrm{C}\left(150,180,210\right.$, and $\left.240{ }^{\circ} \mathrm{C}\right)$ showed inferior device performance in terms of $\mathrm{V}_{\mathrm{TH}}$ and $\mu_{\mathrm{e}}$ (Figure $\mathrm{S} 4$ and $\mathrm{S} 5$ ) as discussed below. The operational stability for all devices in air ambient condition under constant bias (at $V_{D}$ and $V_{G}=60 \mathrm{~V}$ over $600 \mathrm{~s}$ ) was further investigated (see Figure S6). The normalized $\mathrm{I}_{\mathrm{D}}$ of the P(NDIOD-HO) devices decayed by $8.3 \%$ from its initial value, while the P(NDIO-EH) and P(NDIOD-EH) devices exhibited $16.6 \%$ and $12.0 \%$ reduction in $I_{D}$, respectively, reflecting that the chargecarrier trapping in the bulk or at the interface was relatively small for P(NDIOD-HO) transistor.

\section{Figure 3}

In order to clarify the effect of side chains on the thin film surface morphology, which may closely relate to the device performance, we carried out atomic force microscopy (AFM) measurements. As shown in Figure 4, the phase-mode AFM image of the P(NDIO-EH) film revealed randomly distributed nanoscale aggregates with considerably coarse domains in height-mode AFM image (root-mean-square roughness $\left.\left(\mathrm{R}_{\mathrm{RMS}}\right)=3.11 \mathrm{~nm}\right)$. Nano-aggregates of the $\mathrm{P}(\mathrm{NDIO}-\mathrm{EH})$ polymer can be attributed to the presence of linear n-octyl side chain in the NDI moiety, which was also reported for a linear n-octyl side chain on a PDI moiety. ${ }^{45}$ In addition, the low Mw of P(NDID-EH) could have a strong tendency to aggregate and the resulting grain boundaries between crystalline domains can reduce the charge mobility. Interestingly, on the contrary, a nanofiber-like morphology for $\mathrm{P}(\mathrm{NDIOD}-\mathrm{EH})$ and $\mathrm{P}(\mathrm{NDIOD}-\mathrm{HO})$ was presented in the phase-mode AFM images. In addition, relatively smooth surfaces were found in height-mode AFM images for $\mathrm{P}(\mathrm{NDIOD}-\mathrm{EH})$ and $\mathrm{P}(\mathrm{NDIOD}-\mathrm{HO})$ thin 
films $\left(\mathrm{R}_{\mathrm{RMS}}=0.93 \mathrm{~nm}\right.$ for $\mathrm{P}\left(\mathrm{NDIOD}-\mathrm{EH}\right.$ and $\mathrm{R}_{\mathrm{RMS}}=1.27 \mathrm{~nm}$ for $\mathrm{P}(\mathrm{NDIOD}-\mathrm{HO})$. Here it is noteworthy that the diameter and length of $15 \sim 20 \mathrm{~nm}$ and $50 \sim 150 \mathrm{~nm}$ were estimated as evident from the AFM images. Hence, the relatively better electron transport seen in $\mathrm{P}(\mathrm{NDIOD}-\mathrm{EH})$ and $\mathrm{P}(\mathrm{NDIOD}-\mathrm{HO})$, as compared to $\mathrm{P}(\mathrm{NDIO}-\mathrm{EH})$, can be related to the wellaligned nanofiber-like and smooth surface morphology of the thin films.

\section{Figure 4}

The nanostructure of the three NDI-based polymers was investigated using synchrotron GIXD technique in order to account for the impact of the structural changes on the electron transport characteristics in the various materials. As shown in Figure 5a, the (100) Debye ring was clearly observed in the 2D GIXD image of the P(NDIO-EH) layer, implying the presence of randomly oriented crystallites, while noticeable (100), (001), and (010) peaks in the out-ofplane (OOP) direction and a (100) peak in the in-plane (IP) direction were measured for the $\mathrm{P}(\mathrm{NDIOD}-\mathrm{EH})$ film, indicating the co-existence of edge-on and face-on chain stacking (note that the azimuthal angle $(\alpha), \alpha=0^{\circ}$ and $\alpha= \pm 90^{\circ}$, indicates the OOP and IP directions, respectively). Furthermore, the $\mathrm{P}(\mathrm{NDIOD}-\mathrm{HO})$ film exhibited more pronounced (100) and (001) peaks in the OOP direction than those in the IP direction. Looking closely at the 1D profiles in Figure 5b, the (100) peak position of the $\mathrm{P}(\mathrm{NDIOD}-\mathrm{EH})$ polymer thin film was noticeably shifted toward the low scattering vector $(q)$, compared to that of $\mathrm{P}(\mathrm{NDIO}-\mathrm{EH})$ thin film owing to the different lamellar d-spacing values of $19.04 \AA\left(q=0.33 \AA^{-1}\right)$ and $22.44 \AA(q$ $=0.28 \AA^{-1}$ ) for the $\mathrm{P}(\mathrm{NDIO}-\mathrm{EH})$ and $\mathrm{P}(\mathrm{NDIOD}-\mathrm{EH})$ polymers, respectively (here we note that $q$ and $d$ are defined as $q=(4 \pi / \lambda) \sin (\theta)=2 \pi / d$, respectively, where $d$ and $\theta$ are $d$-spacing and half of the scattering angle, respectively). On the contrary, a prominent (100) peak in the 
OOP direction for the $\mathrm{P}(\mathrm{NDIOD}-\mathrm{HO})$ thin film was observed at $0.21 \AA^{-1}$ (d-spacing value = $29.92 \AA$ A), implying a significantly improved crystallinity in the OOP direction. The pronounced edge-on orientation of the $\mathrm{P}(\mathrm{NDIOD}-\mathrm{HO})$ polymer thin film can be crucial for promoting charge transport in the in-plane direction.

\section{Figure 5 and Table 1}

The chain orientation distribution was obtained by extracting the peak intensity versus scattering vector $(q)$ as a function of azimuthal angle (alpha, $\alpha$ ) from the corresponding $2 \mathrm{D}$ GIXD images. Here we note that the ratio of chain orientation was determined by the ratio of the entire area to the integration area of $\alpha=-15^{\circ} \sim+15^{\circ}$ for edge-on chain stacking and $\alpha=-$ $90^{\circ} \sim-75^{\circ}$ and $75^{\circ} \sim 90^{\circ}$ for face-on chain stacking (Figure 6a and $6 \mathrm{~b}$ ). The P(NDIO-EH) layer showed a mainly random orientation $(56.7 \%)$ rather than edge-on and/or face-on chain orientation, whereas the $\mathrm{P}(\mathrm{NDIOD}-\mathrm{EH})$ thin film exhibited a relatively clear bimodal distribution (edge-on (44.2\%) versus face-on (23.3\%)). However, the P(NDIOD-HO) thin film predominantly exhibited an edge-on orientation (74.6\%), which was close to the unimodal orientation. Here it is noteworthy that the population of edge-on chain orientation for the $\mathrm{P}(\mathrm{NDIOD}-\mathrm{HO})$ thin film annealed at above $120{ }^{\circ} \mathrm{C}$ decreased, which is in agreement with the reduction in the field-effect mobility (see Figure S7). Given the GIXD results, the charge transport in triple-bond conjugated NDI copolymers strongly correlated with the coexistence of edge-on and face-on crystallites. As can be seen from Figure 6c, the charge transport in $\mathrm{P}(\mathrm{NDIO}-\mathrm{EH})$ and $\mathrm{P}(\mathrm{NDIOD}-\mathrm{EH})$ layers can be highly limited by the randomly oriented nanocrystalline domains; however, the edge-on orientation in P(NDIOD-HO) thin film can facilitate charge transport in the lateral direction. 


\section{Figure 6}

\section{CONCLUSIONS}

In conclusion, three triple bond-conjugated n-type polymers by introducing different alkyl side chains at the nitrogen-atoms of the imide rings and 2,5-positions of 1,4diethynylbenzene via Sonogashira coupling polymerization were synthesized. Distinct changes in the optical absorption of the three copolymers in the solid state were observed. A more pronounced ICT peak for the $\mathrm{P}(\mathrm{NDIOD}-\mathrm{EH})$ thin film than for the $\mathrm{P}(\mathrm{NDIO}-\mathrm{EH})$ layer was observed and the optical absorption spectrum of the P(NDIOD-HO) thin film was significantly shifted towards the deep red and/or near-infrared region as compared to $\mathrm{P}(\mathrm{NDIO}-\mathrm{EH})$ and $\mathrm{P}(\mathrm{NDIOD}-\mathrm{EH})$ thin films because of the pronounced ICT between the electron-deficient NDI unit and electron-rich hexadecyloxy side chain. When employed as the charge-transporting materials in thin-film transistors, all polymers showed typical electron transporting characteristics due to suitable charge injection from the S-D electrodes to the LUMO energy level of all polymers. In particular, P(NDIOD-HO) transistors exhibited a higher electron mobility value $\left(0.016 \mathrm{~cm}^{2} \mathrm{~V}^{-1} \mathrm{~s}^{-1}\right)$ than those measured for P(NDIO-EH) and $\mathrm{P}(\mathrm{NDIOD}-\mathrm{EH})$ polymer-based devices, indicating that the side chain on the polymer backbone has a significant influence on the charge transport. The latter observation was attributed to the different surface morphology/nanostructure of the resulting polymer thin films. Specifically, the nano-aggregated surface and randomly oriented nanocrystalline domains observed for the $\mathrm{P}(\mathrm{NDIO}-\mathrm{EH})$ layers most likely limits charge transport. This is not the case for the $\mathrm{P}(\mathrm{NDIOD}-\mathrm{EH})$ and $\mathrm{P}(\mathrm{NDIOD}-\mathrm{HO})$ layers both of which exhibited wellaligned nanofiber-like surface morphologies with relatively smooth surfaces. More 
importantly, a coexistence of edge-on and face-on chain stacking (bimodal orientation) was identified in the $\mathrm{P}(\mathrm{NDIOD}-\mathrm{EH})$ layer with the $\mathrm{P}(\mathrm{NDIOD}-\mathrm{HO})$ layers exhibiting a dominant edge-on orientation close to the unimodal orientation, thus facilitating the charge transport in the in-plane direction. Hence, it is evident that the side chains at the imide rings and the triple-bond linkers influences the thin film nanostructure as well as the optoelectronic properties, and surface morphology, thus governing the charge transport. Further enhancement of charge carrier mobility can be expected when different side chains are introduced into triple bond-conjugated polymers.

\section{ASSOCIATED CONTENT}

\section{Supporting Information}

This material is available free of charge via the Internet at http://pubs.acs.org. ${ }^{1} \mathrm{H}$ NMR spectrum, UV-visible absorption spectra for solutions and thin films, $\mathrm{I}_{\mathrm{D}}{ }^{0.5}$ vs $\mathrm{V}_{\mathrm{G}}$ curves, transistor characteristics of $\mathrm{P}(\mathrm{NDIOD}-\mathrm{HO})$ devices annealed at above $120{ }^{\circ} \mathrm{C}$, operational stability, and GIXD data for P(NDIOD-HO) thin films according to the annealing temperature.

\section{AUTHOR INFORMATION}

\section{Corresponding Author}

*E-mail: donal.bradley@mpls.ox.ac.uk (Donal D. C. Bradley).

*E-mail: ykimm@knu.ac.kr (Youngkyoo Kim). 


\section{Notes}

The authors declare no competing financial interest.

\section{- ACKNOWLEDGMENT}

This work was financially supported by grants from the Korean Government (NRF_2016H1D5A1910319, NRF_2017M2A2A4A01071010, NRF_2015R1A2A2A01003743, Basic Science Research Program_2009-0093819).

\section{- REFERENCES}

(1) Zhao, Y.; Guo, Y.; Liu, Y., 25th anniversary article: Recent advances in n-type and ambipolar organic field-effect transistors. Adv. Mater. 2013, 25, 5372-5391.

(2) Sommer, M., Conjugated polymers based on naphthalene diimide for organic electronics. J. Mater. Chem. C 2014, 2, 3088-3098.

(3) Choi, J.; Song, H.; Kim, N.; Kim, F. S., Development of n-type polymer semiconductors for organic field-effect transistors. Semicond. Sci. Technol. 2015, 30, 064002.

(4) Zhan, X.; Facchetti, A.; Barlow, S.; Marks, T. J.; Ratner, M. A.; Wasielewski, M. R.; Marder, S. R., Rylene and related diimides for organic electronics. Adv. Mater. 2011, 23, 268-284.

(5) Facchetti, А., П-conjugated polymers for organic electronics and photovoltaic cell applications†. Chem. Mater. 2011, 23, 733-758.

(6) Ostroverkhova, O., Organic optoelectronic materials: Mechanisms and applications. 
Chem. Rev. 2016, 116, 13279-13412.

(7) Wang, Y.; Michinobu, T., Benzothiadiazole and its $\pi$-extended, heteroannulated derivatives: Useful acceptor building blocks for high-performance donor-acceptor polymers in organic electronics. J. Mater. Chem. C 2016, 4, 6200-6214.

(8) Lei, T.; Dou, J. H.; Ma, Z. J.; Yao, C. H.; Liu, C. J.; Wang, J. Y.; Pei, J., Ambipolar polymer field-effect transistors based on fluorinated isoindigo: High performance and improved ambient stability. J. Am. Chem. Soc. 2012, 134, 20025-20028.

(9) Yue, W.; Nikolka, M.; Xiao, M.; Sadhanala, A.; Nielsen, C. B.; White, A. J. P.; Chen, H.-Y.; Onwubiko, A.; Sirringhaus, H.; McCulloch, I., Azaisoindigo conjugated polymers for high performance n-type and ambipolar thin film transistor applications. $J$. Mater. Chem. C 2016, 4, 9704-9710.

(10) Park, J. H.; Jung, E. H.; Jung, J. W.; Jo, W. H., A fluorinated phenylene unit as a building block for high-performance n-type semiconducting polymer. Adv. Mater. 2013, $25,2583-2588$.

(11) Zhao, Z.; Yin, Z.; Chen, H.; Zheng, L.; Zhu, C.; Zhang, L.; Tan, S.; Wang, H.; Guo, Y.; Tang, Q.; Liu, Y., High-performance, air-stable field-effect transistors based on heteroatom-substituted naphthalenediimide-benzothiadiazole copolymers exhibiting ultrahigh electron mobility up to $8.5 \mathrm{~cm} \mathrm{~V}^{-1} \mathrm{~s}^{-1}$. Adv. Mater. 2017, 29, 1602410.

(12) Fallon, K. J.; Wijeyasinghe, N.; Manley, E. F.; Dimitrov, S. D.; Yousaf, S. A.; Ashraf, R. S.; Duffy, W.; Guilbert, A. A. Y.; Freeman, D. M. E.; Al-Hashimi, M.; Nelson, J.; Durrant, J. R.; Chen, L. X.; McCulloch, I.; Marks, T. J.; Clarke, T. M.; Anthopoulos, T. D.; Bronstein, H., Indolo-naphthyridine-6,13-dione thiophene building block for conjugated polymer electronics: Molecular origin of ultrahigh n-type mobility. Chem. Mater. 2016, 28, 8366-8378. 
(13) Shahid, M.; McCarthy-Ward, T.; Labram, J.; Rossbauer, S.; Domingo, E. B.; Watkins, S. E.; Stingelin, N.; Anthopoulos, T. D.; Heeney, M., Low band gap selenophenediketopyrrolopyrrolepolymers exhibiting high and balanced ambipolar performance in bottom-gate transistors. Chem. Sci. 2012, 3, 181-185.

(14) Wurthner, F.; Stolte, M., Naphthalene and perylene diimides for organic transistors. Chem. Commun. 2011, 47, 5109-5115.

(15) Anthony, J. E.; Facchetti, A.; Heeney, M.; Marder, S. R.; Zhan, X., N-type organic semiconductors in organic electronics. Adv. Mater. 2010, 22, 3876-3892.

(16) Nielsen, C. B.; Turbiez, M.; McCulloch, I., Recent advances in the development of semiconducting dpp-containing polymers for transistor applications. Adv. Mater. 2013, $25,1859-1880$.

(17) Quinn, J. T. E.; Zhu, J.; Li, X.; Wang, J.; Li, Y., Recent progress in the development of n-type organic semiconductors for organic field effect transistors. J. Mater. Chem. C 2017, $5,8654-8681$.

(18) Kim, G.; Kang, S. J.; Dutta, G. K.; Han, Y. K.; Shin, T. J.; Noh, Y. Y.; Yang, C., A thienoisoindigo-naphthalene polymer with ultrahigh mobility of $14.4 \mathrm{~cm}^{2} / \mathrm{Vs}$ that substantially exceeds benchmark values for amorphous silicon semiconductors. J. Am. Chem. Soc. 2014, 136, 9477-9483.

(19) Takai, A.; Chen, Z.; Yu, X.; Zhou, N.; Marks, T. J.; Facchetti, A., Annulated thienylvinylene-thienyl building blocks for $\pi$-conjugated copolymers: Ring dimensions and isomeric structure effects on $\pi$-conjugation length and charge transport. Chem. Mater. 2016, 28, 5772-5783.

(20) Di Pietro, R.; Nasrallah, I.; Carpenter, J.; Gann, E.; Kölln, L. S.; Thomsen, L.; Venkateshvaran, D.; O'Hara, K.; Sadhanala, A.; Chabinyc, M.; McNeill, C. R.; 
Facchetti, A.; Ade, H.; Sirringhaus, H.; Neher, D., Coulomb enhanced charge transport in semicrystalline polymer semiconductors. Adv. Funct. Mater. 2016, 26, 8011-8022.

(21) Matsidik, R.; Komber, H.; Luzio, A.; Caironi, M.; Sommer, M., Defect-free naphthalene diimide bithiophene copolymers with controlled molar mass and high performance via direct arylation polycondensation. J. Am. Chem. Soc. 2015, 137, 67056711.

(22) Matsidik, R.; Luzio, A.; Hameury, S.; Komber, H.; McNeill, C. R.; Caironi, M.; Sommer, M., Effects of pndit2 end groups on aggregation, thin film structure, alignment and electron transport in field-effect transistors. J. Mater. Chem. C 2016, 4, 10371-10380.

(23) Wang, Z.; Li, X.; Zou, Y.; Tan, J.; Fu, X.; Liu, J.; Xiao, C.; Dong, H.; Jiang, W.; Liu, F.; Zhen, Y.; Wang, Z.; Russell, T. P.; Hu, W., Tuning charge transport from unipolar (ntype) to ambipolar in bis(naphthalene diimide) derivatives by introducing $\pi$-conjugated heterocyclic bridging moieties. J. Mater. Chem. C 2016, 4, 7230-7240.

(24) Fei, Z.; Han, Y.; Martin, J.; Scholes, F. H.; Al-Hashimi, M.; AlQaradawi, S. Y.; Stingelin, N.; Anthopoulos, T. D.; Heeney, M., Conjugated copolymers of vinylene flanked naphthalene diimide. Macromolecules 2016, 49, 6384-6393.

(25) Zhang, L.; Rose, B. D.; Liu, Y.; Nahid, M. M.; Gann, E.; Ly, J.; Zhao, W.; Rosa, S. J.; Russell, T. P.; Facchetti, A.; McNeill, C. R.; Brédas, J.-L.; Briseno, A. L., Efficient naphthalenediimide-based hole semiconducting polymer with vinylene linkers between donor and acceptor units. Chem. Mater. 2016, 28, 8580-8590.

(26) Kim, R.; Amegadze, P. S. K.; Kang, I.; Yun, H.-J.; Noh, Y.-Y.; Kwon, S.-K.; Kim, Y.-H., High-mobility air-stable naphthalene diimide-based copolymer containing extended $\pi$ conjugation for n-channel organic field effect transistors. Adv. Funct. Mater. 2013, 23, 
5719-5727.

(27) Guo, X.; Kim, F. S.; Seger, M. J.; Jenekhe, S. A.; Watson, M. D., Naphthalene diimidebased polymer semiconductors: Synthesis, structure-property correlations, and nchannel and ambipolar field-effect transistors. Chem. Mater. 2012, 24, 1434-1442.

(28) Chen, H.; Guo, Y.; Mao, Z.; Yu, G.; Huang, J.; Zhao, Y.; Liu, Y., Naphthalenediimidebased copolymers incorporating vinyl-linkages for high-performance ambipolar fieldeffect transistors and complementary-like inverters under air. Chem. Mater. 2013, 25, $3589-3596$.

(29) Hwang, Y.-J.; Murari, N. M.; Jenekhe, S. A., New n-type polymer semiconductors based on naphthalene diimide and selenophene derivatives for organic field-effect transistors. Polym. Chem. 2013, 4, 3187-3195.

(30) Fukuta, S.; Wu, H.-C.; Koganezawa, T.; Isshiki, Y.; Ueda, M.; Chen, W.-C.; Higashihara, T., Synthesis and fet characterization of novel ambipolar and low-bandgap naphthalene-diimide-based semiconducting polymers. J. Polym. Sci. A 2016, 54, 359367.

(31) Zhao, M.; Hashimoto, K.; Tajima, K., Synthesis of copolymer based on naphthalene diimide connected with a non-conjugated flexible linker. Synth. Met. 2013, 175, 9-14.

(32) Chen, H.; Liu, Z.; Zhao, Z.; Zheng, L.; Tan, S.; Yin, Z.; Zhu, C.; Liu, Y., Synthesis, structural characterization, and field-effect transistor properties of n-channel semiconducting polymers containing five-membered heterocyclic acceptors: Superiority of thiadiazole compared with oxadiazole. ACS Appl. Mater. Interfaces 2016, $8,33051-33059$.

(33) Kim, Y.; Long, D. X.; Lee, J.; Kim, G.; Shin, T. J.; Nam, K.-W.; Noh, Y.-Y.; Yang, C., A balanced face-on to edge-on texture ratio in naphthalene diimide-based polymers with 
hybrid siloxane chains directs highly efficient electron transport. Macromolecules 2015, $48,5179-5187$.

(34) An, Y.; Long, D. X.; Kim, Y.; Noh, Y. Y.; Yang, C., Improved electron transport properties of n-type naphthalenediimide polymers through refined molecular ordering and orientation induced by processing solvents. Phys. Chem. Chem. Phys. 2016, 18, 12486-12493.

(35) Hillebrandt, S.; Adermann, T.; Alt, M.; Schinke, J.; Glaser, T.; Mankel, E.; HernandezSosa, G.; Jaegermann, W.; Lemmer, U.; Pucci, A.; Kowalsky, W.; Mullen, K.; Lovrincic, R.; Hamburger, M., Naphthalene tetracarboxydiimide-based n-type polymers with removable solubility via thermally cleavable side chains. ACS Appl. Mater. Interfaces 2016, $8,4940-4945$.

(36) Bucella, S. G.; Luzio, A.; Gann, E.; Thomsen, L.; McNeill, C. R.; Pace, G.; Perinot, A.; Chen, Z.; Facchetti, A.; Caironi, M., Macroscopic and high-throughput printing of aligned nanostructured polymer semiconductors for mhz large-area electronics. Nat. Commun. 2015, 6, 8394.

(37) Gao, L.; Zhang, Z.-G.; Xue, L.; Min, J.; Zhang, J.; Wei, Z.; Li, Y., All-polymer solar cells based on absorption-complementary polymer donor and acceptor with high power conversion efficiency of $8.27 \%$. Adv. Mater. 2016, 28, 1884-1890.

(38) Kang, B.; Kim, R.; Lee, S. B.; Kwon, S. K.; Kim, Y. H.; Cho, K., Side-chain-induced rigid backbone organization of polymer semiconductors through semifluoroalkyl side chains. J. Am. Chem. Soc. 2016, 138, 3679-3686.

(39) Zhao, X.; Ma, L.; Zhang, L.; Wen, Y.; Chen, J.; Shuai, Z.; Liu, Y.; Zhan, X., An acetylene-containing perylene diimide copolymer for high mobility n-channel transistor in air. Macromolecules 2013, 46, 2152-2158. 
(40) Alvey, P. M.; Ono, R. J.; Bielawski, C. W.; Iverson, B. L., Conjugated ndi-donor polymers: Exploration of donor size and electrostatic complementarity. Macromolecules 2013, 46, 718-726.

(41) Kola, S.; Kim, J. H.; Ireland, R.; Yeh, M.-L.; Smith, K.; Guo, W.; Katz, H. E., Pyromellitic diimide-ethynylene-based homopolymer film as an n-channel organic field-effect transistor semiconductor. ACS Macro Lett. 2013, 2, 664-669.

(42) Alvey, P. M.; Iverson, B. L., Reactions of brominated naphthalene diimide with bis(tributylstannyl)acetylene: Asimpleapproach for conjugated polymers and versatile coupling intermediates. Org. Lett. 2012, 14, 2706-2709.

(43) Sajoto, T.; Tiwari, S. P.; Li, H.; Risko, C.; Barlow, S.; Zhang, Q.; Cho, J.-Y.; Brédas, J.L.; Kippelen, B.; Marder, S. R., Synthesis and characterization of naphthalene diimide/diethynylbenzene copolymers. Polymer 2012, 53, 1072-1078.

(44) Fudickar, W.; Linker, T., Why triple bonds protect acenes from oxidation and decomposition. J. Am. Chem. Soc. 2012, 134, 15071-15082.

(45) Hahm, S. G.; Rho, Y.; Jung, J.; Kim, S. H.; Sajoto, T.; Kim, F. S.; Barlow, S.; Park, C. E.; Jenekhe, S. A.; Marder, S. R.; Ree, M., High-performance n-channel thin-film fieldeffect transistors based on a nanowire-forming polymer. Adv. Funct. Mater. 2013, 23, 2060-2071.

(46) Nam, S.; Han, H.; Seo, J.; Song, M.; Kim, H.; Anthopoulos, T. D.; McCulloch, I.; Bradley, D. D. C.; Kim, Y., Ambipolar organic phototransistors with p-type/n-type conjugated polymer bulk heterojunction light-sensing layers. Adv. Electron. Mater. 2016, 2, 1600264.

(47) Bottacchi, F.; Bottacchi, S.; Spath, F.; Namal, I.; Hertel, T.; Anthopoulos, T. D., Nanoscale charge percolation analysis in polymer-sorted $(7,5)$ single-walled carbon 
nanotube networks. Small 2016, 12, 4211-21. 
(a)<smiles>[R7]C1=C([R])c2c(Br)cc3c4c(c(Br)cc(c24)C1=O)C(=O)N([R1])C3=O</smiles>

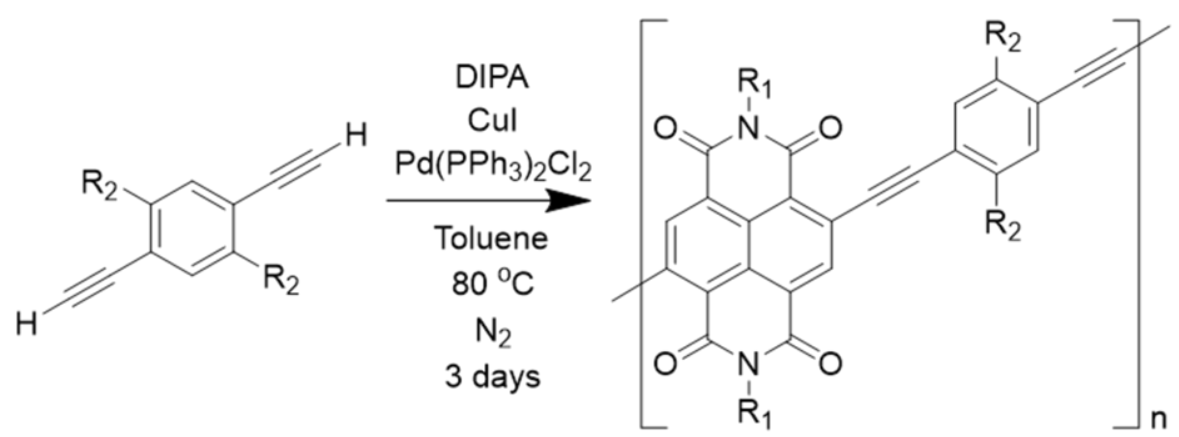

$\mathrm{R}_{1}=\mathrm{n}$-Octyl, Octyldodecyl

$\mathrm{R}_{2}=$ Ethylhexyl, $\mathrm{n}$-Hexadecyloxy

(b)

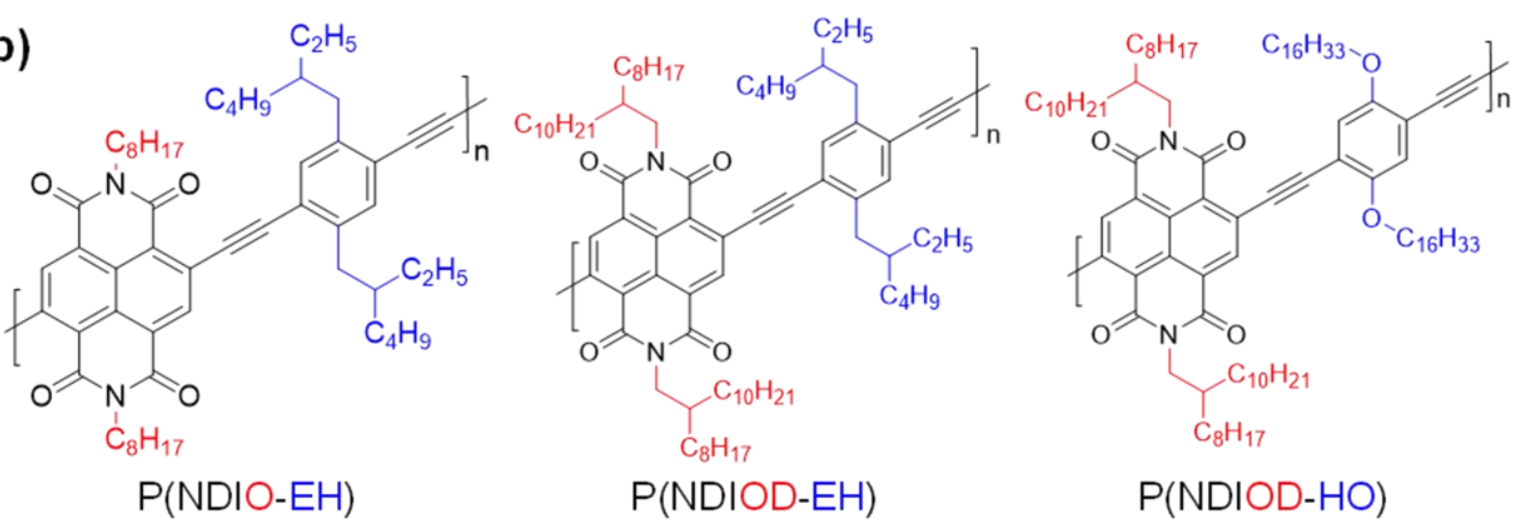

(c)

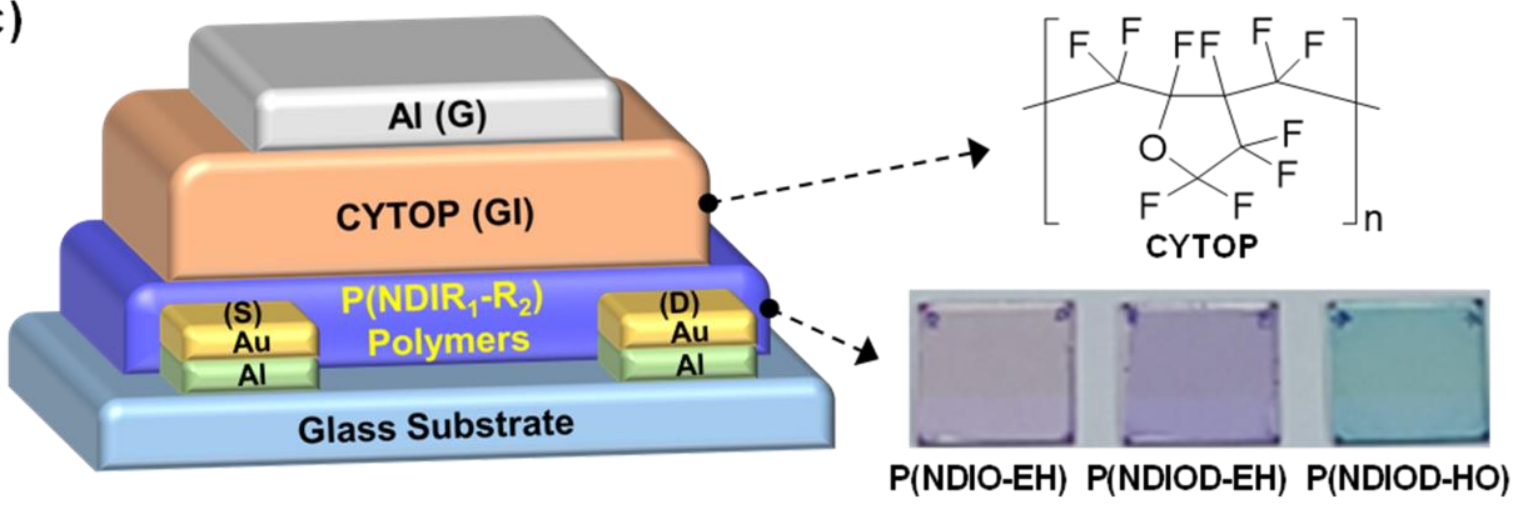

Figure 1. (a) Synthesis of P(NDI-R1-R2) polymers via Sonogashira coupling reaction. (b) Chemical structure of triple bond-conjugated NDI-based copolymers. (c) Device structure of top gate/bottom contact field-effect transistors with P(NDIR1-R2) polymers, chemical structure for gate-insulating polymer, CYTOP and film images for each polymer. 
(a)

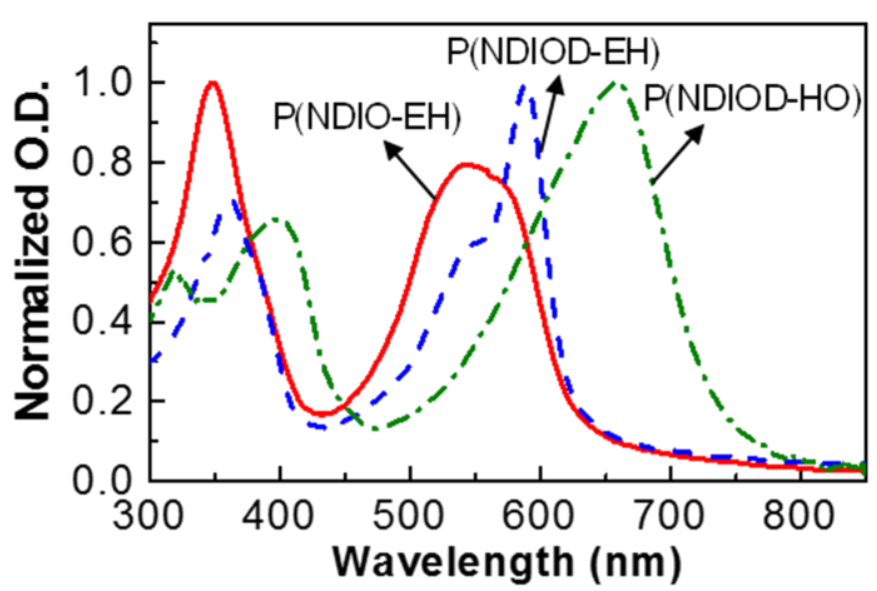

(b)

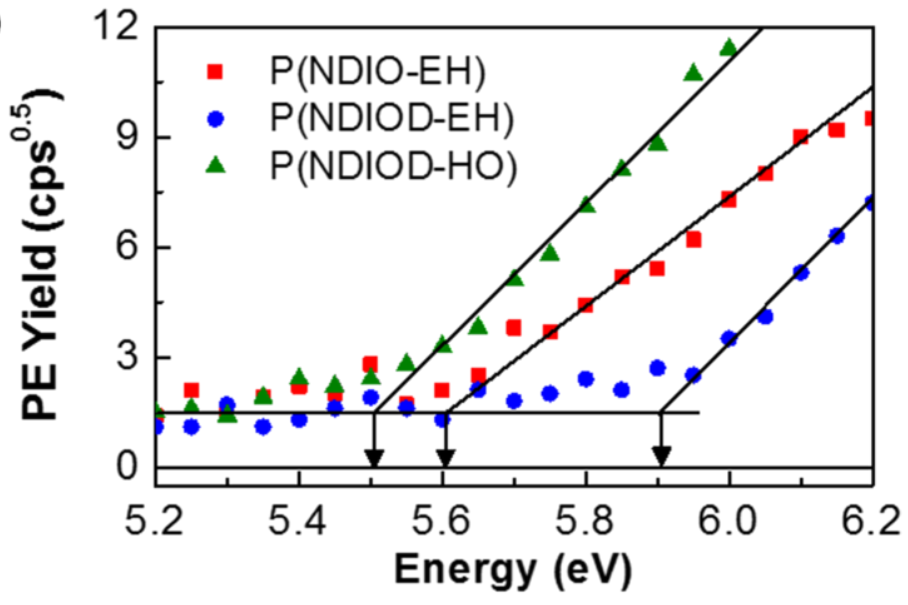

(c)

Vacuum Level

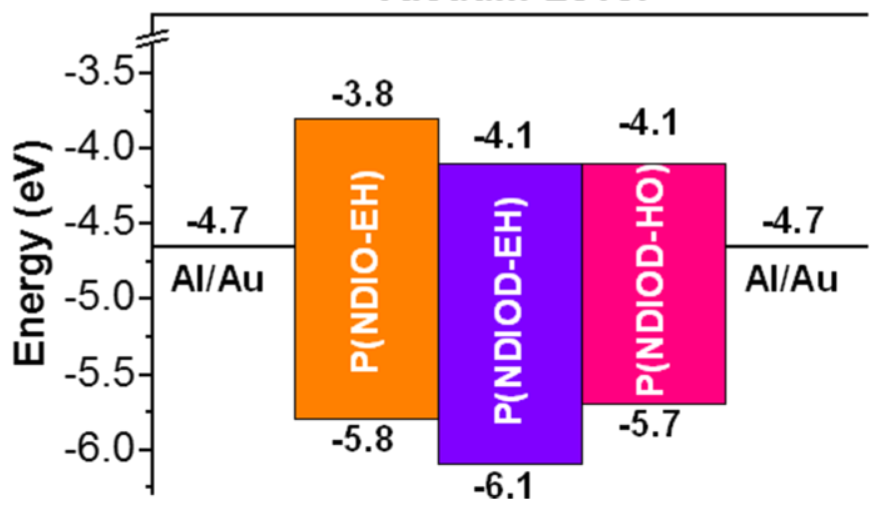

Figure 2. (a) Normalized optical density (O.D.) and (b) photoelectron yield spectra (PEYS) of triple bond-conjugated NDI-based copolymers films coated on quartz and ITO-glass substrates, respectively. (c) Flat energy band diagram for field-effect transistors with three NDI-based copolymers. 
(a)
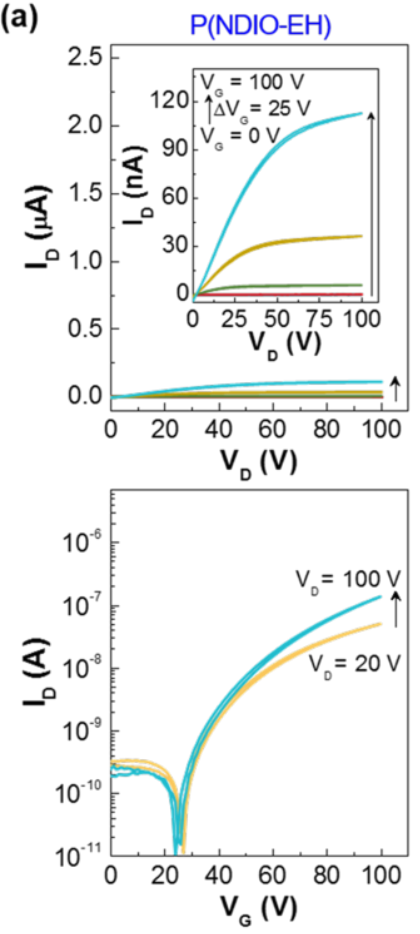

$\mathrm{P}$ (NDIOD-EH)
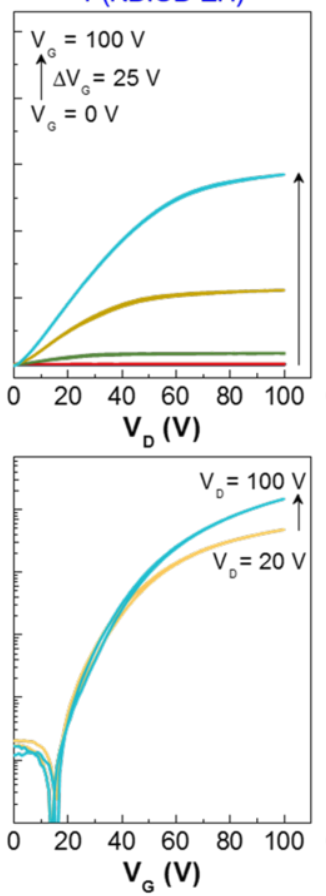

$\mathrm{P}(\mathrm{NDIOD}-\mathrm{HO})$
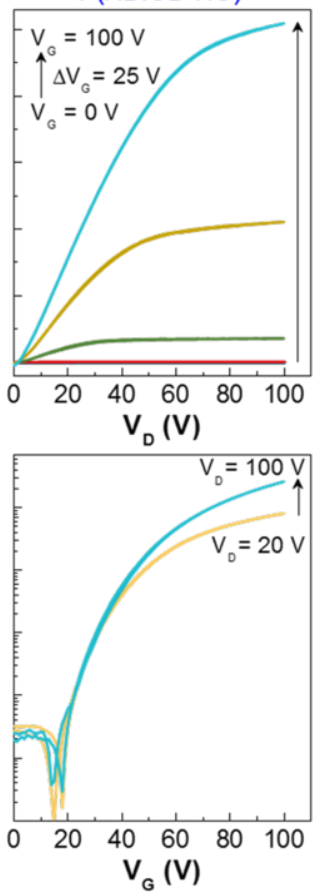

(b)
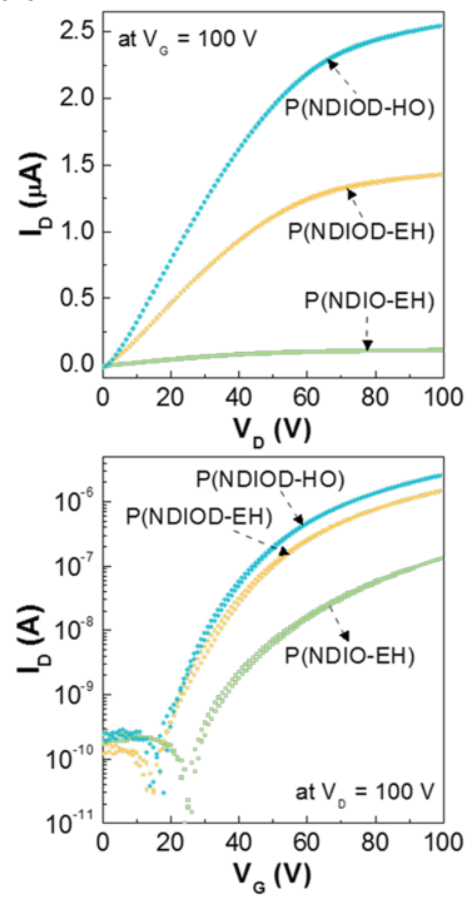

Figure 3. (a) Output and transfer curves for field-effect transistors based on three NDI-based copolymers and (b) representative output (at $\mathrm{V}_{\mathrm{G}}=100 \mathrm{~V}$ ) and transfer curves (at $\mathrm{V}_{\mathrm{D}}=100 \mathrm{~V}$ ) for transistors based on three NDI-based copolymers. 
(a)

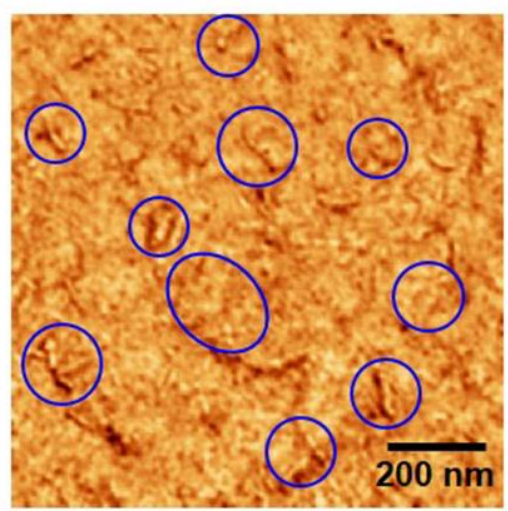

(b)

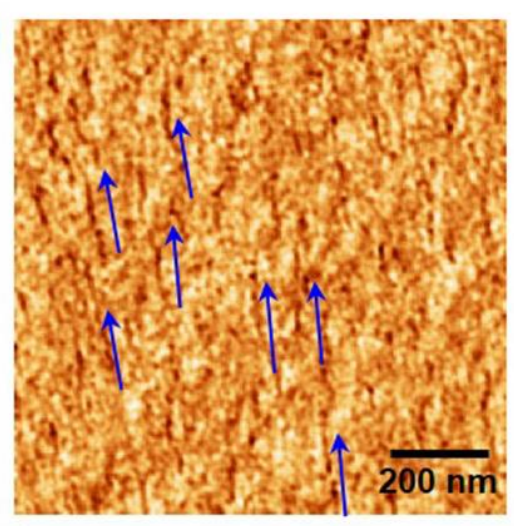

(c)

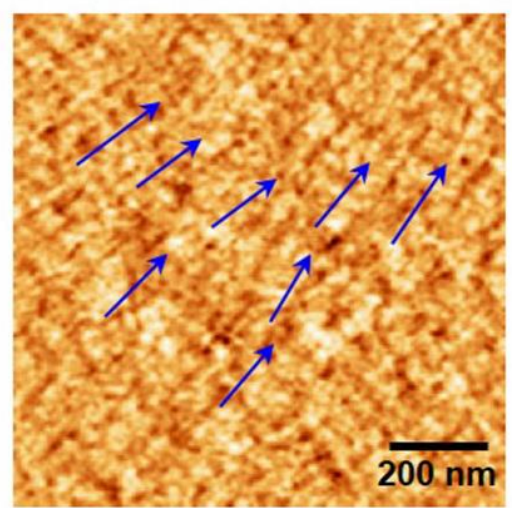

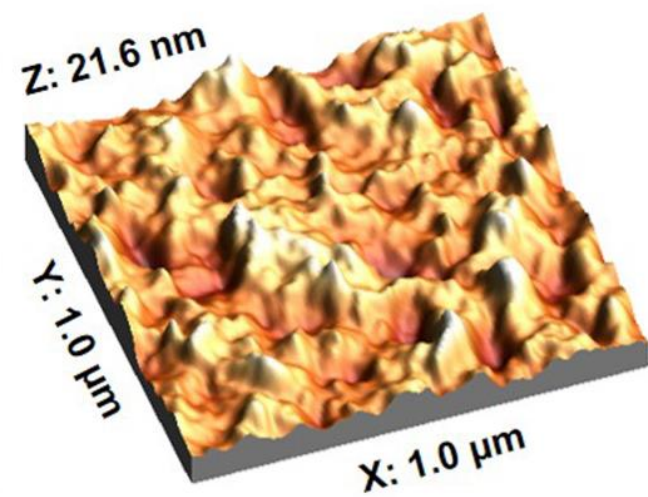
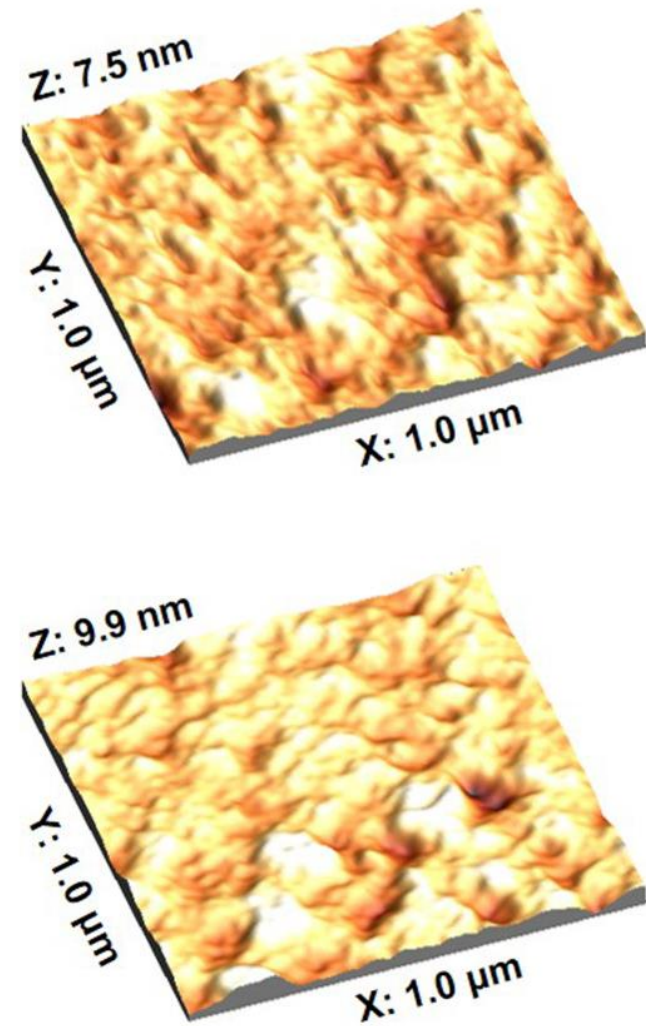

Figure 4. Phase-mode (left) and 3D height-mode (right) AFM images $(1 \mu \mathrm{m} \times 1 \mu \mathrm{m})$ : (a) $\mathrm{P}(\mathrm{NDIO}-\mathrm{EH})$, (b) P(NDIOD-EH), and (c) P(NDIOD-HO) thin film. Note that the nanoaggregates and nanofiber-like parts are marked with circles and arrows, respectively. 
(a)
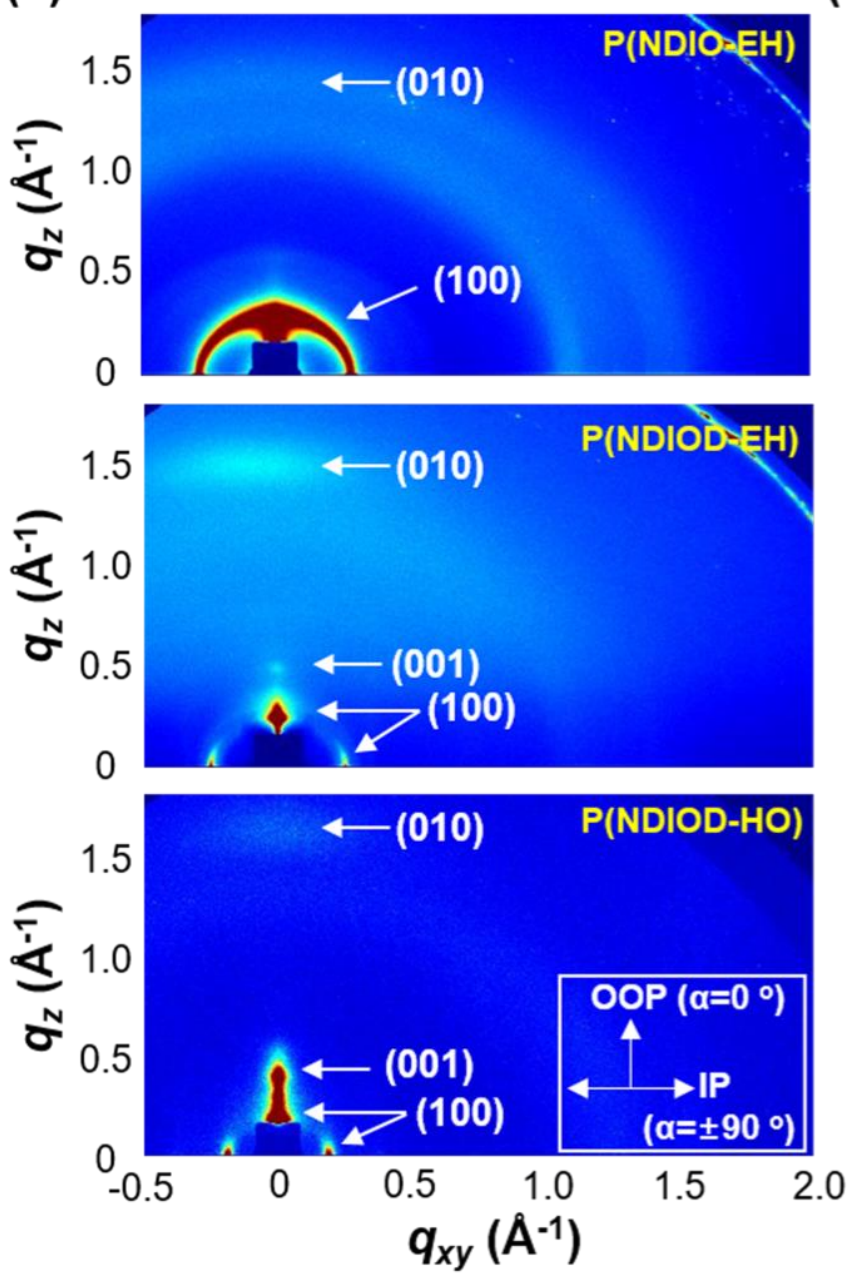

(b)
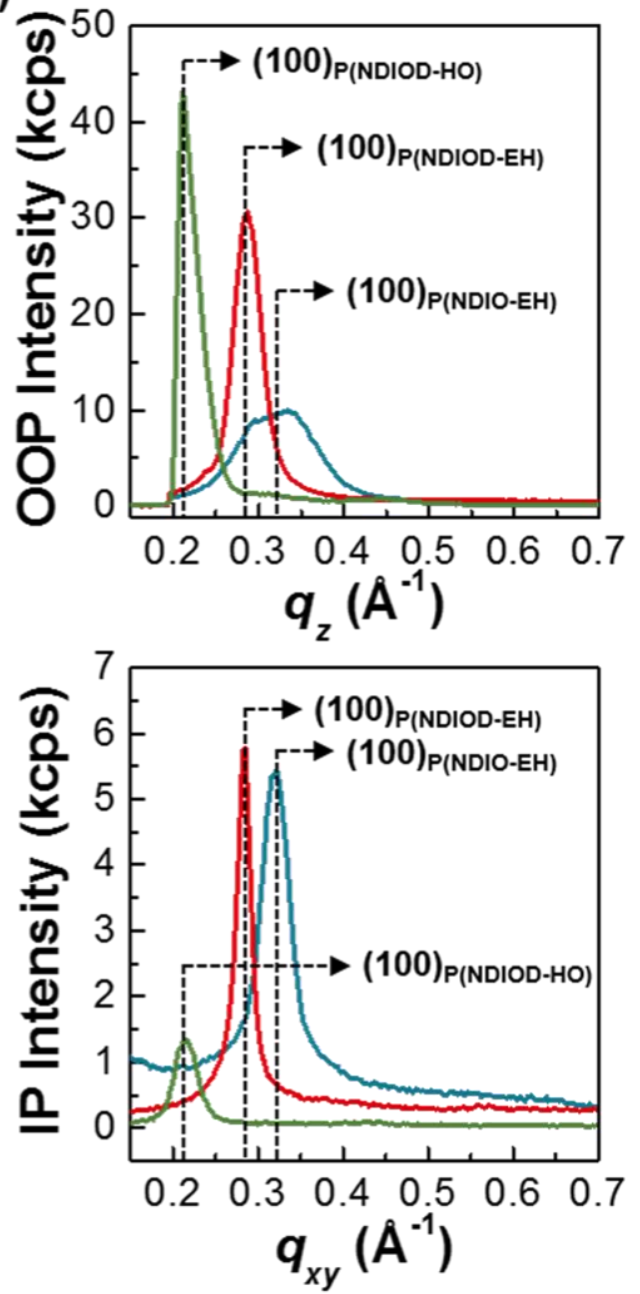

Figure 5. (a) 2D GIXD images and (b) 1D profiles for P(NDIO-EH), P(NDIOD-EH), and $\mathrm{P}(\mathrm{NDIOD}-\mathrm{HO})$ thin films annealed at $120{ }^{\circ} \mathrm{C}$ coated on silicon substrate. The main diffraction peaks for each polymer are marked inside the 2D GIXD images and 1D profiles. 
(a)

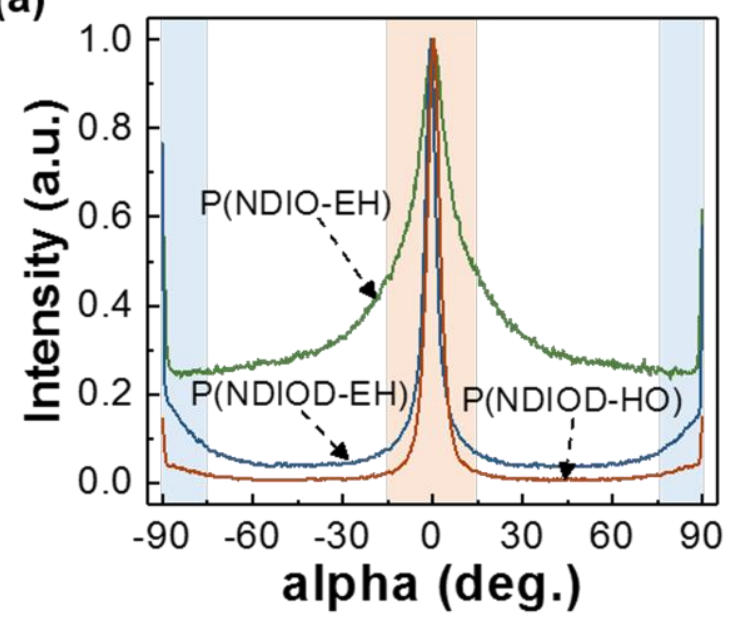

(b)

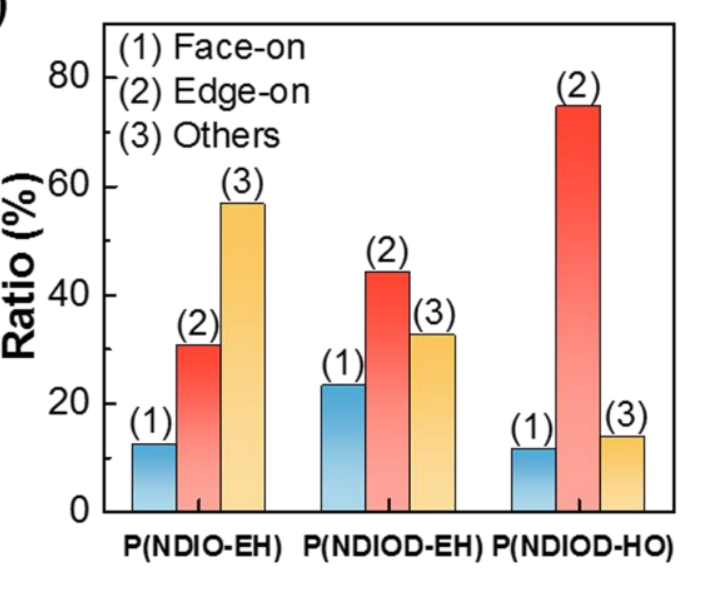

(c)

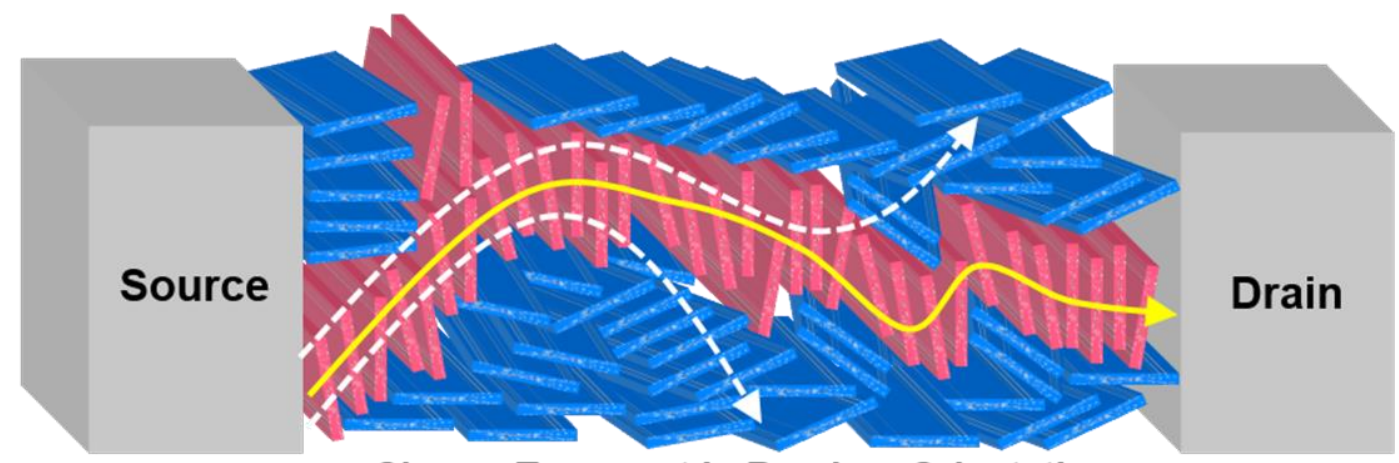

< Charge Transport in Random Orientation>

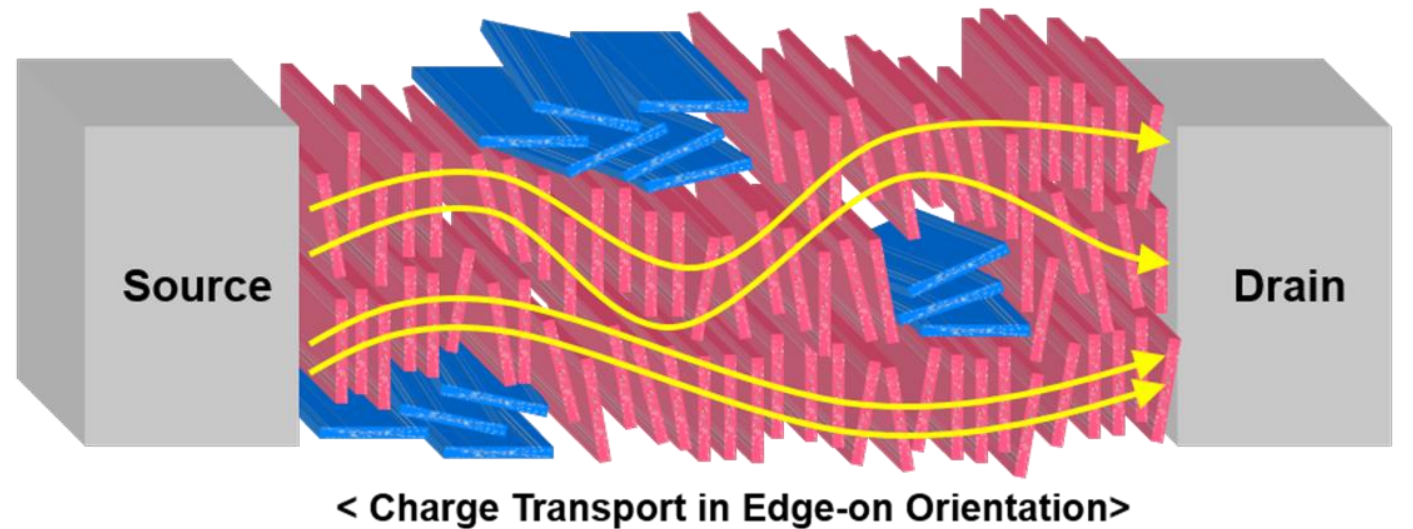

Figure 6. (a) Intensity for (100) peak of each polymer as a function of azimuthal angle (alpha). (b) Ratio for face-on, edge-on, and other orientations (note that the ratio of chain orientation was determined by the ratio of the entire area to the integration area of $\alpha=-15^{\circ} \sim$ $15^{\circ}$ for edge-on chain stacking, $\alpha=-90^{\circ} \sim-75^{\circ}$ and $75^{\circ} \sim 90^{\circ}$ for face-on chain stacking, and $\alpha=-90^{\circ} \sim-75^{\circ}$ and $75^{\circ} \sim 90^{\circ}$ for other chain stacking). (c) Illustration of charge transport in random orientation (top) and edge-on orientation (bottom). 
Table 1. Summary of weight-average molecular weight (Mw), polydispersity index (PDI), energy levels, device performance parameters, and d-spacing values for the three NDI-based copolymers.

\begin{tabular}{|c|c|c|c|c|c|c|c|c|c|c|}
\hline Material & $\begin{array}{c}\mathrm{Mw} \\
(\mathrm{kDa})\end{array}$ & PDI & $\begin{array}{l}\text { HOMO } \\
(\mathrm{eV})\end{array}$ & $\begin{array}{l}\text { LUMO } \\
(\mathrm{eV})\end{array}$ & $\begin{array}{c}\mathrm{Eg} \\
(\mathrm{eV})\end{array}$ & $\begin{array}{c}\mu_{\mathrm{e}} \\
\left(\mathrm{cm}^{2} \mathrm{~V}^{-1} \mathrm{~s}^{-1}\right)\end{array}$ & $\begin{array}{l}\mathrm{V}_{\mathrm{TH}} \\
(\mathrm{V})\end{array}$ & $\mathrm{I}_{\mathrm{D}, \mathrm{ON} / \mathrm{OFF}}$ & $\begin{array}{c}\text { d-spacing } \\
\text { (alkyl- } \\
\text { alkyl) } \\
(\AA)\end{array}$ & $\begin{array}{c}\text { d-spacing } \\
(\pi-\pi) \\
(\AA)\end{array}$ \\
\hline $\begin{array}{c}\mathrm{P}(\mathrm{NDIO}- \\
\mathrm{EH})\end{array}$ & 7.5 & 1.56 & -5.8 & -3.8 & 2.0 & 0.0011 & 42.8 & 2300 & 19.04 & 4.19 \\
\hline $\begin{array}{l}\text { P(NDIOD- } \\
\text { EH) }\end{array}$ & 56.7 & 2.56 & -6.1 & -4.1 & 2.0 & 0.0092 & 31.3 & 38000 & 22.44 & 4.05 \\
\hline $\begin{array}{c}\text { P(NDIOD- } \\
\mathrm{HO})\end{array}$ & 117 & 1.84 & -5.7 & -4.0 & 1.7 & 0.016 & 30.7 & 41000 & 29.92 & 3.81 \\
\hline
\end{tabular}




\section{<TOC Graphic >}

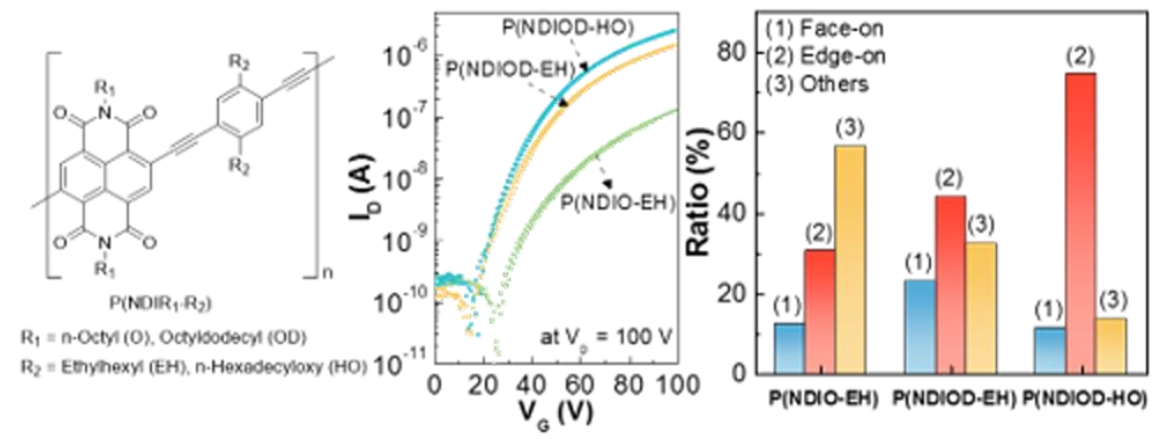

